\section{Claude Luezior ou le train de la vie}

Laurent Bayart

Déjà Claude Monet lorsqu'il présenta en 1887 la série de ses toiles de la gare Saint-Lazare avait, en précurseur de son art, trouvé de la poésie dans la beauté grave des trains poussiéreux. Plus loin dans le temps, le romancier Claude Luezior nous propose l'émotion impressionniste de sa poésie où la touche passionnelle et affective se trouve omniprésente.

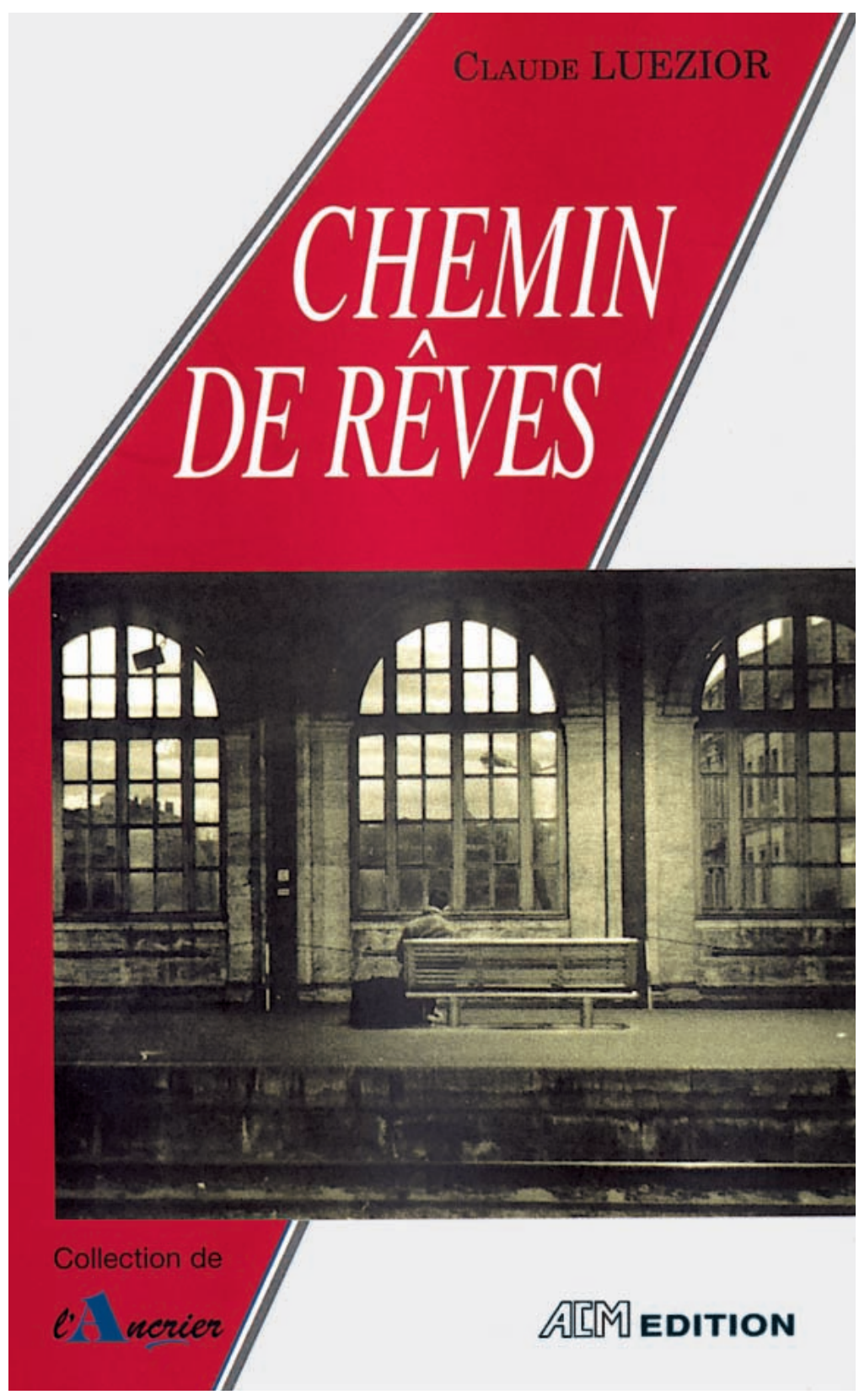

Justement son nouveau livre [1] nous entraîne dans l'ambiance trépignante des gares qui sont en quelque sorte le théâtre de l'humaine condition.

Faut-il encore présenter cet écrivain-neurologue suisse dont les ouvrages sont autant de succès et de multiplications des pains de la réédition? D’ailleurs, son écriture romanesque possède la singularité d'être sertie, sinon truffée de poésie, ce qui est somme toute extrêmement rare chez un romancier, à telle enseigne, qu'en le lisant, on se demande d'où lui vient ce talent qui lui permet de conjuguer avec autant de bonheur ces deux temps d'un même verbe de la discipline littéraire! Humaniste, que le terme fut galvaudé en cette fin de siècle et de millénaire, et pourtant s'il en est pour mériter ce titre, c'est bien Claude Luezior.

Avec ce Chemin de rêves, à l'image de Christian Bobin, il nous rappelle judicieusement que la poésie c'est suivre son coeur en allant à la fête [2]. Et justement, avec un sens inné de l'observation et d'une extrême acuité sensorielle, il nous emmène dans les festivités des rendez-vous de hasard où les chemins se croisent, bifurquent, marquent un temps d'arrêt avant de s'afficher sur des panneaux électroniques pour faire rêver le voyageur à d'exotiques et d'imprévisibles pèlerinages. Gares où se côtoie, s'emmêle, se mélange l'étrange alchimie des chemineaux en quête de destinations, qu'elles soient kilométriques, pour la plupart ou philosophiques et métaphysiques pour quelques rares initiés, qui voient dans les gares de fines métaphores et autres allégories de l'existence; ces lieux portent les mots dans le mystère des voyages immobiles.

Et voici que Luezior, par l'enchantement de la plume, nous fait vivre ces heures de luminescence que l'on partage dans ces endroits de passage où les comédiens investissent à chaque moment le paysage pour "reformater» à nouveau le décor de leur propre âme. Défile devant nos yeux la multitude des individus qui sont comme des essaims de gestes et de paroles sur la ruche bourdonnante des quais: vieillards, militaires, hommes d'affaires (avec les attributs virils de cette fin de siècle: le téléphone portable, la carte enfichable, la calculette jetable), enfants, mères de famille, clochards, voyageurs en transit, amoureux ... nous voilà confondus dans le rythme enivrant des haleines partagées et des tutoiements de la vue. Avec un talent à la sensibilité tellurique, il nous raconte ces aventures passionnantes et quotidiennes, écartelées, écorchées, drôles, cocasses et parfois même aussi dramatiques. A l'écouter (car il y a de l'écoute dans cette lecture là), on ne peut s'empêcher de penser à la Bête humaine de Zola: danses hydrauliques des cylindres; le dinosaure chuchote ses mâchonnements et articule ses wagons comme d'immenses vertèbres. A travers le jeu d'un dialogue furtif entre les textes, notre narrateur installe magnifiquement ses situations, et pour reprendre l'image employée plus haut, ses tableaux: des fois quand je viens ici, j'ai l'impression d'être dans une cathédrale où tout est possible. Tout est dit, écrit, décrit avec justesse et finesse, à tel point que l'on y retrouve l'ambiance et l'atmosphère de ces attentes habitées qui permettent à l'âme de se recons- 
tituer en observant les gens s'affairer autour de soi. Ainsi, lorsque des Africains débarquent avec leurs vêtements disparates et colorés, voilà que des soleils tatouent les pilastres d'étranges hosties. Quelques jupes bigarrées emmêlent leurs affleurements et les poitrines chaudes ballottent leurs mélopées d'amour / Ce train décline ses tam-tams du fond des tripes / L'Afrique est venue. Ceci à l'adresse de ces frères à la peau noire, mais il y a aussi le déferlement des enfants, ceux qui sous la toise se mesurent en graduation de trois pommes: les gamins ont une tendance fâcheuse et immédiate à disperser les consignes. Sac de bille grand ouvert. C'est la loi de l'entropie maximale ... Il y a de la poésie partout dans cette prose qui déroule lentement sa narration et sa respiration, en un endroit où même les clients réservant leurs billets deviennent des disciples de ... Platon s'adonnant à la philosophie appliquée des distances à parcourir. Ici, c'est le temps qui se fige et qui nous regarde avec ces dizaines de cadrans présents à chaque instant pour que le train parte pas sans ses conquistadors. C'est le lieu mystique des espaces qui se croisent et du magnétisme des êtres en partance, en fuite ou en transhumance: on voit le pôle positif des retrouvailles et le pôle négatif des départs. Stefan Zweig, grand voyageur devant l'éternel écrivait déjà: rouler, c'est la quiétude, voyager, c'est faire halte dans l'inquiétude du monde [3].
Laissez-vous emporter par ces billets découverts par Rita sur un quai; poésie de gare qui aurait recouvré toute la noblesse des contemplations, cette écriture est tout simplement magistrale car elle prend le temps de nous transporter dans l'Orient-Express de notre imaginaire. Aujourd'hui, le culte de la vitesse ne nous fait hélas, plus gagner de temps mais bel et bien perdre notre humanité. Claude Luezior, c'est ce monsieur au sourire tendre et à la moustache joviale, assis sur un banc de ce quai, qui prend plaisir à regarder passer les express et les omnibus, dans un brouhaha d'enfer. Sa force est de n'attendre aucun train et de n'être prisonnier d'aucune contrainte horaire. Avec sérénité, il observe ce tohu-bohu de fin de siècle qui brasse les courants d'air. Il sait très bien que toutes les destinations mènent au même terminus. Et que la vie n'est qu'une immense gare.

Le contrôleur vous le confirmera bien le moment venu.

\section{Littérature}

1 Luezior C. Chemin de rêves. Strasbourg: ACM Edition; 2000.

2 Bobin C. L'épuisement. Le temps qu'il fait; 1994.

3 Zweig S. Journaux (1912-1940). Le Livre de Poche; 1995.
} 